\title{
Spermiogram and sperm reserves in hybrid Bos indicus $x$ Bos taurus bulls after scrotal insulation
}

\author{
S. Wildeus and K. W. Entwistle \\ Department of Tropical Veterinary Science, James Cook University, Townsville, Queensland 4811, \\ Australia
}

\begin{abstract}
Summary. Scrotal insulation for $48 \mathrm{~h}$ raised subcutaneous scrotal temperature by $4^{\circ} \mathrm{C}$ in hybrid Bos indicus $\times$ Bos taurus bulls. The incidence of decapitated spermatozoa in the ejaculate increased significantly between 6 and 14 days and that of protoplasmic droplets and tail abnormalities between 20 and 23 days after insulation, respectively. Simultaneously, the percentages of spermatozoa with lost and damaged acrosomes increased significantly 12-17 days after insulation. At slaughter 23 days after scrotal insulation sperm production rates and gonadal reserves had not been affected by insulation, but epididymal reserves were markedly reduced, particularly in the cauda. Elevated testicular temperature therefore had an effect on immature spermatozoa in the caput epididymidis and on spermatids, but it is suggested that selective sperm resorption in the rete testis and excurrent ducts may prevent some of these changes being expressed in the ejaculate.
\end{abstract}

\section{Introduction}

Zebu (Bos indicus) cattle are widely used throughout the tropical regions of the world because of their production advantages under these environmental conditions. Zebu bulls generally show a greater physiological adaptability to high temperatures and humidity than do bulls of the Bos taurus type (Johnston, Naelepaa \& Frye, 1963; Skinner \& Louw, 1966). However Singleton (1974) found the same degree of testicular and epididymal degeneration in both species once the thermoregulatory threshold was passed or eliminated. There is also conflicting evidence regarding the susceptibility of bovine epididymal spermatozoa to heat stress, since some studies were unable to demonstrate any effect of scrotal insulation on epididymal spermatozoa (Austin, Hupp \& Murphee, 1961 ; Ross \& Entwistle, 1979), while others have suggested early morphological changes in the ejaculate after scrotal insulation to be of epididymal origin (El-Azab, 1969; Singleton, 1974). Similarly, Igboeli \& Rakha (1971) observed an increase in secondary sperm abnormalities during the tropical hot season in zebu bulls, which they attributed to impaired epididymal function under heat stress.

As part of a research programme on the use of Bos indicus $\times$ Bos taurus bulls under tropical conditions, and in an attempt to clarify the nature of heat-induced changes on epididymal function, the effects of short-term scrotal insulation on early changes in the morphology of ejaculated spermatozoa and on gonadal and epididymal sperm reserves were examined. 


\section{Materials and Methods}

Animals. The 10 bulls used in this experiment were $\mathrm{F}_{2}$ generation half-Brahman cross bulls aged 2.5-4.5 years of age. The genetic background of these animals has been described by Salim \& Entwistle (1982). The animals were allocated by stratified randomization based on liveweight into control $(\mathrm{N}=5)$ and treatment $(\mathrm{N}=5)$ groups. Throughout the experiment the bulls were kept on native pasture and given native grass hay as a supplement to maintain liveweight. To accustom the range-reared bulls to frequent handling and to stabilize extragonadal sperm reserves, semen samples were collected by electroejaculation at 3-day intervals during a 4-week pre-experimental period.

Experimental procedures. Two days before scrotal insulation temperature probes were implanted subcutaneously in the mid-posterior region of the scrotum of each bull under local anaesthesia. The probes were prepared from linear temperature transducers (AD-590, Parameter Pty Ltd, Australia) which had an accuracy of $0 \cdot 1{ }^{\circ} \mathrm{C}$ over the measuring range $\left(30-40^{\circ} \mathrm{C}\right)$. The probes were embedded in epoxy resin with a final outer diameter of $5 \mathrm{~mm}$, and the transducers were connected by wires sealed in medical grade Silastic tubing (o.d. $2.7 \mathrm{~mm}$ : Dow Corning, Midland, Michigan, U.S.A.), the exterior parts of the wires being loosely attached to the abdominal skin. Temperatures were recorded in restrained animals using an electronic thermometer, which had individually calibrated circuits for each probe. For insulation a pouch, consisting of an inner layer of plastic and aluminium foil and an outer layer of rubber-lined calico with a 3-cm layer of wool clippings between them, was placed over the scrotum, glued to the abdominal skin (Austin et al., 1961), and left in place for $48 \mathrm{~h}$.

Subcutaneous scrotal, rectal and ambient dry bulb temperatures were recorded daily at $09: 00$, $12: 00,18: 00$ and $24: 00 \mathrm{~h}$, over a 6-day period before, during and after insulation. After removal of the insulation pouch, semen was collected by electroejaculation for the next 23 days, initially at 2day intervals for the first 14 days and subsequently every 3rd day until slaughter on Day 23. Immediately after the last ejaculation (Day 23) the bulls were transported to a local abattoir, and testes and epididymides were collected at slaughter.

Laboratory procedures. Aliquants of each ejaculate were fixed in phosphate-buffered saline (PBS)-glutaraldehyde (Johnson, Berndtson \& Pickett, 1976) and the spermatozoa were examined under phase-contrast microscopy for morphological changes. These samples were also used to determine sperm concentrations with a haemocytometer. In addition, acrosomal changes were assessed from Giemsa-stained smears under oil immersion, and acrosomal integrity was scored in 4 categories (Watson, 1975).

At slaughter the testes and epididymides were dissected free of connective tissue, the epididymis segmented further into caput, corpus and cauda, and all organ weights recorded. Numbers of spermatids and spermatozoa were determined quantitatively from a sample $(\sim 25 \mathrm{~g})$ of the right testis and from entire segments of epididymis by tissue homogenization and haemocytometer counts (Amann \& Almquist, 1961; Amann \& Lambiase, 1969). Daily testicular sperm production per gram and total daily sperm production were calculated using a time divisor of $5 \cdot 11$ days (Salim \& Entwistle, 1982).

Statistical analyses. Correlation coefficients were calculated to examine relationships of subcutaneous scrotal, rectal and environmental temperatures. Differences in ejaculate characteristics between control and treated bulls were analysed by Student's $t$ test after angular transformation of percentages, while data on testicular and epididymal sperm reserves were subjected to analysis of variance after log transformation, with treatment and age as independent variables.

\section{Results}

In control bulls a uniform pattern of subcutaneous scrotal and rectal temperatures was maintained over the measurement period (Text-fig. 1). Subcutaneous scrotal temperature rose immediately 


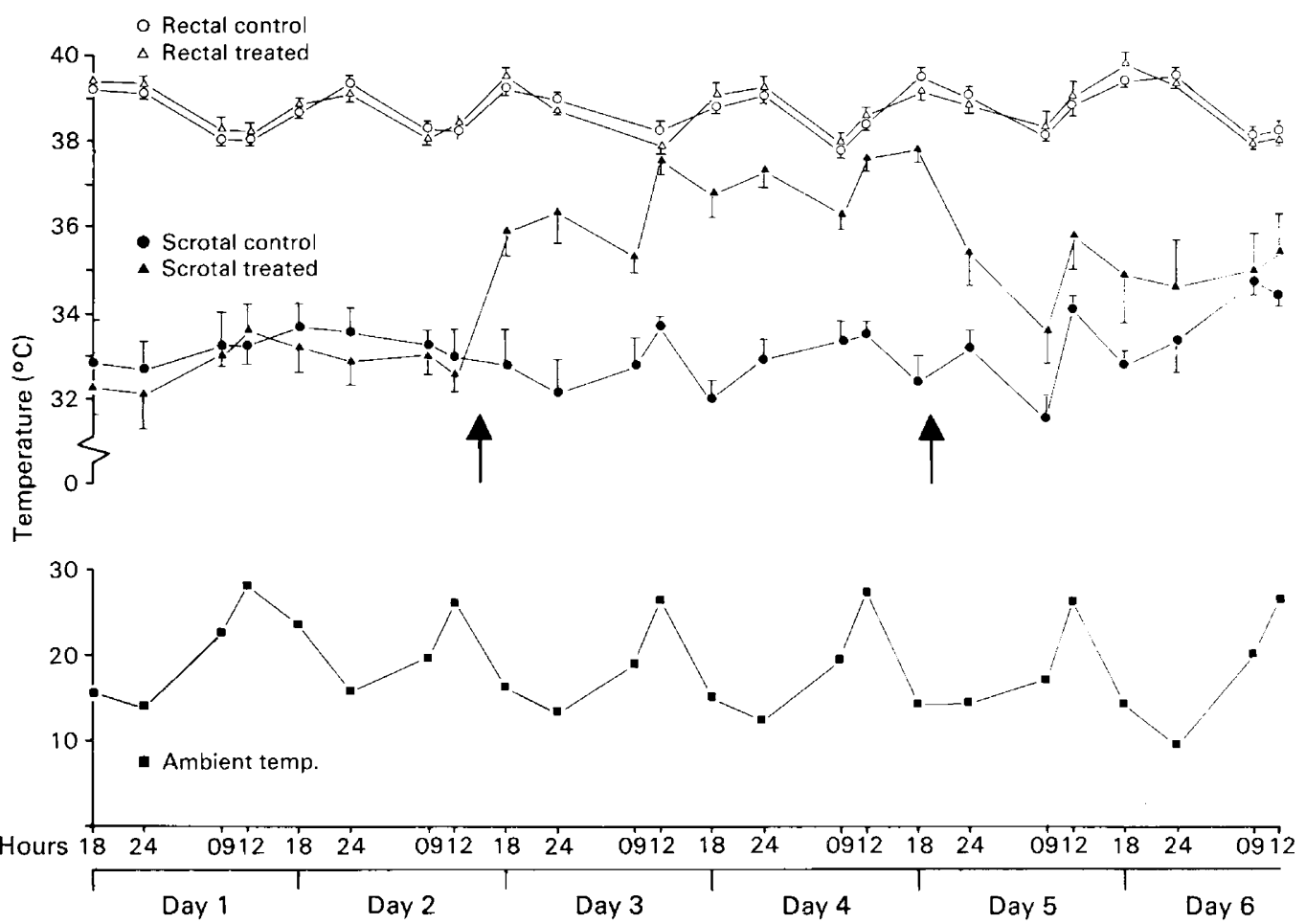

Text-fig. 1. Ambient and mean ( \pm s.d.) subcutaneous scrotal and rectal temperatures in hybrid bulls before, during and after scrotal insulation. Arrows mark the beginning and end of the 48-h insulation period.

after insulation and there was a mean temperature difference of $4.05^{\circ} \mathrm{C}$ between treated and control bulls during insulation. Scrotal temperatures returned to control levels within 2 days after removal of insulation. Subcutaneous scrotal temperature was negatively correlated with rectal temperature $(r=-0.69)$ and positively with ambient temperature $(r=0.75)$ in the control animals $(P<0.05)$. Insulation eliminated the relationship between scrotal and environmental temperatures $(r=$ -0.02 ), but rectal temperatures were not affected by insulation and correlation coefficients between environmental and rectal temperatures were $r=-0.68$ and $r=-0.65$ for insulated and control animals $(P<0.05)$, respectively.

Changes in ejaculate characteristics after scrotal insulation are presented in Text-fig. 2. Scrotal insulation had no significant effect on sperm output per ejaculate during the experimental period, but resulted in a significant increase $(P<0.05)$ in the percentage of abnormal spermatozoa. The chronological occurrence of specific types of abnormalities contributed at distinctly different times to the overall increase in morphologically abnormal spermatozoa. There was a significant $(P<$ 0.05 ) transient increase in the incidence of decapitated spermatozoa in bulls 6-14 days after scrotal insulation, but no significant differences thereafter. The percentage of spermatozoa with abnormal tails increased $(P<0.05)$ at 12 days, and those with protoplasmic droplets at 17 days after insulation and remained high until slaughter at 23 days. The percentage of spermatozoa with abnormal acrosomes increased significantly $(P<0.05) 12$ days after insulation treatment. Testicular weights and estimates of daily sperm production at slaughter were similar $(P<0.05)$ for the scrotally insulated and control bulls (Table 1). However, changes occurred in the epididymis; while epididymal weights were similar, there was a marked reduction in epididymal sperm reserves in the scrotally insulated bulls $\left(9.15 \times 10^{9}\right)$ compared to the control bulls $\left(17.41 \times 10^{9}\right)$. These 


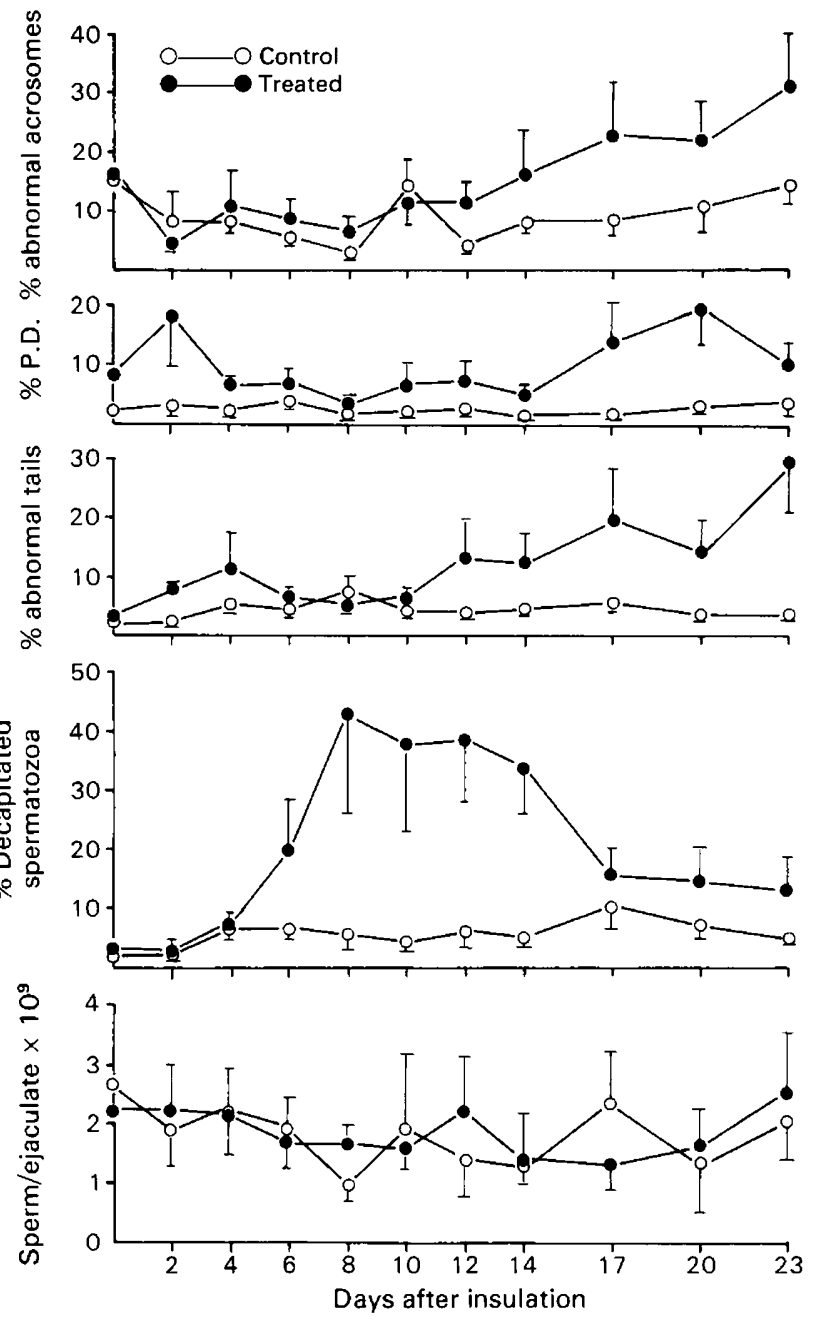

Text-fig. 2. Changes (mean \pm s.e.m.) in sperm output and the percentage of decapitated spermatozoa, abnormal sperm tails, spermatozoa with protoplasmic droplets (P.D.) and abnormal acrosomes in hybrid bulls after scrotal insulation for $48 \mathrm{~h}$.

differences were evident in the caput, but were more pronounced in the cauda epididymidis, where insulation reduced sperm reserves to $39 \%$ of those of the control bulls. The difference was also reflected in a decreased contribution of the cauda to total epididymal sperm reserves for $55 \%$ in control to $41 \%$ in scrotally insulated bulls.

\section{Discussion}

Subcutaneous scrotal temperature measured in a mid-posterior position will give a consistent estimate of changes in testicular temperature (Fowler, 1968) and hence the observed rise of $4^{\circ} \mathrm{C}$ in subcutaneous scrotal temperature is likely to be a reflection of changes in intra-scrotal temperatures. There was a slow return to pre-insulation subcutaneous scrotal temperatures after insulation and a gradual increase in the control bulls, which was attributed to the mild focal inflammatory response evident at the implantation site upon histological examination of skin 
Table 1. Testicular and epididymal weights and sperm reserves (mean \pm s.e.m.) in treated and control bulls 23 days after scrotal insulation for $48 \mathrm{~h}$

\begin{tabular}{|c|c|c|}
\hline Characteristic & $\begin{array}{l}\text { Control } \\
\text { bulls }\end{array}$ & $\begin{array}{l}\text { Scrotally } \\
\text { insulated } \\
\text { bulls }\end{array}$ \\
\hline No. of bulls & 5 & 5 \\
\hline Age (years) & $3 \cdot 3 \pm 0 \cdot 5$ & $2 \cdot 9 \pm 0.5$ \\
\hline Liveweight (kg) & $448 \pm 60 \cdot 9$ & $432 \pm 58$ \\
\hline Wt of paired testes $(\mathrm{g})$ & $418 \cdot 7 \pm 60 \cdot 9$ & $419 \cdot 2 \pm 34 \cdot 6$ \\
\hline $\begin{array}{l}\text { Daily testicular sperm } \\
\text { production/g }\left(\times 10^{6}\right)\end{array}$ & $13 \cdot 46 \pm 0 \cdot 50$ & $14 \cdot 66 \pm 1 \cdot 43$ \\
\hline Total sperm production $\left(\times 10^{9}\right)$ & $5.32 \pm 0.92$ & $5.83 \pm 0.85$ \\
\hline \multicolumn{3}{|l|}{ Wt of paired epididymides $(\mathrm{g})$} \\
\hline Caput & $22 \cdot 28 \pm 3.91$ & $21 \cdot 22 \pm 2 \cdot 66$ \\
\hline Corpus & $5 \cdot 12 \pm 0.88$ & $6.08 \pm 1.37$ \\
\hline Cauda & $12 \cdot 34+0.92$ & $10 \cdot 96+1.68$ \\
\hline \multicolumn{3}{|c|}{ Epididymal sperm reserves $\left(\times 10^{9}\right)^{*}$} \\
\hline Caput & $6.59 \pm 1.88$ & $3.81 \pm 1 \cdot 51$ \\
\hline Corpus & $1.29 \pm 0.33$ & $1.62 \pm 1.07$ \\
\hline Cauda & $9 \cdot 53 \pm 2.49$ & $3.72 \pm 1.63$ \\
\hline
\end{tabular}

* Determined unilaterally from right side.

sections post mortem. The immediate result of scrotal insulation appears to be a breakdown of heat exchange across the scrotum, reflected in the absence of a correlation between scrotal and enviromental temperatures. The response to scrotal insulation in these hybrid bulls, however, was restricted to the scrotum and did not involve a simultaneous decline in body temperature as has been reported for the ram (Waites, 1962).

The changes in ejaculate characteristics show that mild testicular heating, through short periods of scrotal insulation, is sufficient to cause sperm degeneration. The nature and sequence of the morphological changes agree with those of earlier reports for Bos taurus bulls (Lagerlof, 1934; Austin et al., 1961; Gustafsson, 1966), but the severity of the response varied between animals, despite a uniform increase in scrotal temperatures due to insulation. The incidence of decapitated spermatozoa returned to normal after 14 days and the time of appearance of such spermatozoa suggests that this abnormality originates during sperm transit through the caput epididymidis. The rise of tail abnormalities 12 days after insulation coincides with the time of sperm metamorphosis (Courot, Hochereau-de Reviers \& Ortavant, 1970), and the gradual transition between decapitated spermatozoa and tail abnormalities in the ejaculate is a result of the heterogeneous nature of the epididymal sperm population in regard to age (Koefoed-Johnsen, 1960). The time and nature of the acrosomal changes (Text-fig. 2) agree with the electron microscopic findings of Williamson (1974) for rams and appear to occur during acrosome formation at the late spermatid stage (Courot et al., 1970).

While scrotal insulation had no effect on testicular sperm production and reserves, considerable differences were found in the epididymal reserves 23 days after insulation; a reduction that was not evident from the sperm output and concentration in the ejaculate at the ejaculation frequency employed in this experiment. It has been suggested that the bovine epididymis is capable of sperm resorption (Amann \& Almquist, 1962), and qualitative electron microscopic findings of sperm resorption in the rete testis (Sinowatz, Wrobel, Sinowatz \& Kugler, 1979; Goyal, 1982) and efferent ductules (Crabo, Gustafsson, Nicander \& Rao, 1971) seem to validate the earlier finding. Furthermore sperm resorption was found to be associated with abnormal spermiograms (Rao, Bane \& Gustafsson, 1980) and decapitated spermatozoa to be particularly susceptible to resorption (Crabo et al., 1971). These findings indicate that the observed reduction in epididymal sperm reserves in the scrotally insulated bulls may be a reflection of increased resorption of abnormal 
spermatozoa. An alternative explanation for the reduction in epididymal sperm reserves would be a reduced epididymal transit time and subsequent increases in non-ejaculatory sperm loss. This appears unlikely, however, since Ross \& Entwistle (1979) and Koefoed-Johnsen (1965) found no changes in epididymal transit time in bulls after scrotal insulation. Hence these results suggest that selective phagocytosis probably conceals some of the early morphological changes after mild testicular heat insult in the ejaculate of hybrid Bos indicus $\times$ Bos taurus bulls.

We thank Mr R. B. Mercer, James Cook University Electronics Section, for help in developing the temperature recording implants. The study was partly financed with funds from the Australian Meat Research Committee.

\section{References}

Amann, R.P. \& Almquist, J.O. (1961) Reproductive capacity of dairy bulls. I. Technique for direct measurement of gonadal and extra-gonadal sperm reserves. J. Dairy Sci. 44, 1537-1543.

Amann, R.P. \& Almquist, J.O. (1962) Reproductive capacity of dairy bulls. IV. Effect of unilateral vasectomy and ejaculation frequency on sperm reserves; aspects of epididymal physiology. $J$. $R e$ prod. Fert. 3, 260-268.

Amann, R.P. \& Lambiase, J.T. (1969) The male rabbit. III. Determination of daily sperm production by means of testicular homogenates. J. Anim. Sci. 28, 369-374.

Austin, J.W., Hupp, E.W. \& Murphee, R.L. (1961) Effect of scrotal insulation on semen of Hereford bulls. $J$. Anim. Sci. 20, 307-310.

Courot, M., Hochereau-de Reviers, M.-T. \& Ortavant, R. (1970) Spermatogenesis. In The Testis, Vol. 1, Ch. 6, pp. 339-433. Eds A. D. Johnson, W. R. Gomes \& N. L. VanDemark. Academic Press, New York.

Crabo, B., Gustafsson, B., Nicander, L. \& Rao, A.R. (1971) Subnormal testicular function in a bull concealed by phagocytosis of abnormal spermatozoa in the efferent ductules. J. Reprod. Fert. 26, 393-396.

El-Azab, E.A. (1969) The effect of heat on the spermatogenesis, sperm morphology and the epididymis in bulls. J. Vet. Sci. U.A.R. 6, 31-40.

Fowler, D.G. (1968) Skinfolds and Merino breeding. 5. Variations in scrotal, testis and rectal temperatures as effected by the site of measurement, acclimatization to heat and degree of skin fold. Aust. J. exp. Agric. Anim. Husb. 8, 125-132.

Goyal, H.O. (1982) Light microscopic and ultrastructural evidence of epithelial phagocytosis of sperm in rete testis and ductuli efferentes in the bull. Am. J. vet. Res. 43, 785-790.

Gustafsson, B. (1966) Luminal contents of the bovine epididymis under conditions of reduced spermatogenesis, luminal blockage and sperm abnormalities. Acta vet. scand., Suppl. 17, 2-80.

Igboeli, G. \& Rakha, A.M. (1971) Seasonal changes in the ejaculate characteristics of Angoni (short horn zebu) bulls. J. Anim. Sci. 33, 651-654.

Johnson, L., Berndtson, W.E. \& Pickett, B.W. (1976) An improved method for evaluating acrosomes of bovine spermatozoa. J. Dairy Sci. 42, 951-954.

Johnston, J.E., Naelapaa, H. \& Frye, J.B., Jr (1963) Physiological responses of Holstein, Brown Swiss and
Red Sinhi crossbred bulls exposed to high temperatures and humidities. J. Anim. Sci. 22, 432-436.

Koefoed-Johnsen, H.H. (1960) Influence of ejaculation frequency on the time required for sperm formation and epididymal passage in the bull. Nature, Lond. $185,49-50$.

Koefoed-Johnsen, H.H. (1965) Indvirkningen af eksperimentelt fremkaldt testisdegeneration pa spermiernes dannelsesog transporttid hos en tyr. Kgl. Vet.-org. Landbohojskole, Aarsberetning. Inst. for Sterilitestforskning, Copenhagen, pp. 133-146.

Lagerlof, N. (1934) Morphologische Untersuchungen uber Veranderungen im Spermabild und in den Hoden bei Bullen mit verminderter oder aufgehobener Fertilitat. Acta path. microbiol. Scand., Suppl. 19, 1-253.

Rao, A.R., Bane, A. \& Gustafsson, B.K. (1980) Changes in the morphology of spermatozoa during their passage through the genital tract in dairy bulls with normal and impaired spermatogenesis. Theriogeno$\log y 14,1-12$.

Ross, A.D. \& Entwistle, K.W. (1979) The effect of scrotal insulation on spermatozoal morphology and the rates of spermatogenesis and epididymal passage of spermatozoa in the bull. Theriogenology 11, 111-129.

Salim, B. \& Entwistle, K.W. (1982) Duration of the seminiferous epithelial cycle in hybrid Bos indicus $\times$ Bos taurus bulls. J. Reprod. Fert. 66, 729-734.

Singleton, E.F. (1974) The effect of heat on reproductive function in the bull. Ph.D. thesis, University of Queensland.

Sinowatz, F., Wrobel, K.-H., Sinowatz, S. \& Kugler, P. (1979) Ultrastructural evidence for phagocytosis of spermatozoa in the bovine rete testis and testicular straight tubules. J. Reprod. Fert. 57, 1-4.

Skinner, J.D. \& Louw, G.N. (1966) Heat stress and spermatogenesis in Bos indicus and Bos taurus cattle. J. appl. Physiol. 21, 1784-1790.

Waites, G.M.H. (1962) The effect of heating the scrotum of the ram on respiration and body temperature. $Q . J l$ exp. Physiol. 47, 314-323.

Watson, P.F. (1975) Use of Giemsa stain to detect changes in acrosomes of frozen ram spermatozoa. Vet. Rec. 97, 12-15.

Williamson, P. (1974) The fine structure of ejaculated ram spermatozoa following scrotal heating. $J$. $R e$ prod. Fert. 40, 191-195. 